\title{
CASE OF FAMILY ATROPHY OF THE PERONEAL TYPE.
}

\author{
By G. L. Walton, M.D.,
}

of BOSTON.

This case accentuates the difficulty in classifying the socalled peroneal type of progressive muscular atrophy.

The history of the family and the physical examination (asicle from the reflexes) of the patient who presented himself at the Neurological Department of the Massachusetts General Hospital, would strongly suggest that in his case at least, we have to do with a dystrophy rather than a spinal (or neural) type of atrophy. At the same time the diminution of deep reflexes in muscles apparently normal, suggests the possibility of a wider distribution of the underlying pathological condition.

The boy is I 5 years of age. He has a brother of 25 who commenced to show a difficulty in walking and wasting of leg muscles at II. The clisturbance progressed in his case very slowly, finally attacking the upper extremities so that the muscles of the hand are now wasted and the movements awkward, but this older brother is still able to work as gate tender, I4 years after the onset of his clisease, and with no suggestion of bulbar involvement.

Another brother of 18 has similar trouble in the legs of some years duration, and of gradual onset.

A third brother of $\mathrm{I} 2$ has complained for some months of slowly increasing clifficulty in walking, resembling that of our patient.

A great-aunt on the maternal sicle is saicl to have become invalicled by a similar trouble. No other instances are known in the family. Three sisters and one brother are unaffected.

In our patient impaiment in the use of the legs appeared at about I I, and has been slowly progressive. There has been no pain, no paresthesia, no numbness, no further complaint of any kincl.

Physical examination shows a boy rather delicately built but of fair muscular development. The face is somewhat pear shaped and symmetrical, the cranium is somewhat tigonal, the ears are fairly well shaped but rather prominent, the left more so than the right. No other signs of deviation are noted. There is no lordosis. The pupils and heart and arteries are normal. There is no involvement of cranial nerves, or of the muscles of the trunk, shoulder or upper extremities.

The gait shows a moderate tendency to toe-clrop, especially 
on the left. Both feet are in the position of cartss. All muscles of the feet and toes are impaired, particularly in the peroneal clistribution. All morements of the thighs are strong, and the nutrition of the thigh muscles is good without suggestion of muscular, adipose, or fibrous enlargement. The calves are comparativcly small, the left one-quarter inch smaller than the right. The legs each measure $32^{1 / 2}$ inches from the crest of the ilium to the inner malleolus. The skin is every where normal, the feet are rather cool, the right somewhat cyanotic. No trace of fibrillary taitching appears on prolonged cramination. The epigastric, abdominal, and cremaster reflexes are lively, the plantar reflex consists of flexion, very slight in clegree. The Achilles reflex is absent on both sides; the knee-jerk is extrencly sluggish. Sensation is everywhere normal, including the thermal and pain senses. The muscles of the lower les show very greatly diminished reaction to both the faradic and galvanic currents without qualitative change. 